\title{
BLOOD FLOW IN THE HAND AND FOREARM AFTER PARAVERTEBRAL BLOCK OF THE SYMPATHETIC GANGLIA. EVIDENCE AGAINST SYMPATHETIC VASODILATOR NERVES IN THE EXTREMITIES OF MAN
}

\author{
By J. V. WARREN, C. W. WALTER, J. ROMANO, aNd E. A. STEAD, JR. \\ (From the Medical Clinic of the Peter Bent Brigham Hospital and the Department of \\ Medicine, Harvard Medical School, Boston)
}

(Received for publication April 29, 1942)

Many of the blood vessels of the extremities are under reflex control. Numerous stimuli, such as cooling the body, pain, loud noise, or deep inspiration, produce reflex vasoconstriction. Heating the body causes reflex vasodilatation. The fact that either pre- or post-ganglionic sympathectomy eliminates these vasoconstrictor and vasodilator responses demonstrates that the sympathetic nerves contain the efferent limb of the reflex arc for both types of response $(1,2)$. These vasomotor reflexes which are mediated through the sympathetic nerves could be explained equally well by either of the following hypotheses: $(a)$ that vasoconstriction is an active process resulting from reflex sympathetic stimulation, and vasodilatation is a passive phenomenon resulting from inhibition or lack of sympathetic activity; (b) that both vasoconstriction and vasodilatation are active processes resulting from reflex activity. The latter hypothesis assumes that part of the reflex vasodilatation results from inhibition of active vasoconstriction, but that vasodilatation beyond that point is an active process resulting from reflex stimulation of the vasodilator nerves. This hypothesis gained support from the demonstration that the sympathetic nerves to the extremities contain both adrenergic and cholinergic fibers. The nerves supplying the sweat fibers are cholinergic, but anatomically they form a part of the sympathetic system. Might it not be possible that vasodilator, cholinergic fibers also coursed through the sympathetic ganglia and nerves?

Lewis and Pickering observed that heating the body was the most satisfactory means of causing neurogenic vasodilatation in the extremities of both normal subjects and patients with Raynaud's disease, and that this response to body heating occurred only in the presence of intact sympathetic innervation (1). They noted that in normal subjects whose skin temperature had previously been lowered by exposure in a cold room, blocking the ulnar nerve caused vasodilatation and warming of the anesthetized fingers. In two of their patients with Raynaud's disease, block of the ulnar nerve did not cause the fourth and fifth fingers to warm. Heating the body produced normal vasodilatation in these fingers. They concluded: "To sum up, it is found in cases of Raynaud's disease exposed to suitable room temperature that ulnar anesthesia, with its inhibition of vasoconstrictor tone, fails to release the vascular spasm, but that under the same conditions, warming the body relaxes the vessels. The last effect occurs through sympathetic paths, failing to occur after sympathectomy, but as it is not due to simple inhibition of vasoconstrictor tone, being, in fact, prevented by anesthetization of the mixed nerve, it must be attributed to active vasodilatation." These experiments are not conclusive because no evidence was obtained to show that the block of the ulnar nerve had actually inhibited the vasoconstrictor impulses to the vessels supplying the fourth and fifth fingers. It has been found that it is not always safe to rely on anesthesia alone as a sign that all sympathetic fibers to the area are blocked (3). Lewis and Pickering (1), estimating changes in blood flow from changes in skin temperature, were unable to obtain evidence of vasodilator nerves in normal subjects. They believed that these negative experiments were not conclusive because changes in blood flow are not always reflected by changes in skin temperature. They pointed out that the loss of vasoconstrictor tone raised the temperature of the part to such a degree that further active vasodilatation had little chance of causing a further rise in skin temperature.

Grant and Holling (3) studied the blood flow in the forearm during intensive body heating. They found that the blood flow increased, and that this increase was dependent on the integrity 
of the sympathetic nerves. Local nerve block, however, caused the anesthetic skin to become pale and cool. "Moreover, if the skin is first flushed and warmed, and kept so by heating the body, and a cutaneous nerve is then blocked (the circulation to the hand being arrested), the area then becomes anesthetic and ceases to sweat, pales and cools." These authors concluded that there are two means of defense against a rise of body temperature. "The first is brought into action by relatively gentle heating and consists chiefly of a dilatation of the arteriovenous anastomoses in the extremities, caused by inhibition of vasoconstrictor tone. The second is added when the heating is more intense and consists mainly of a general dilatation of the cutaneous vessels associated with sweating, both of which are caused by stimulation of the sympathetic nerves." These experiments, too, suggest that the sympathetic nerves carry vasodilator fibers, but they are not conclusive. No data are given to show that novocainization of the peripheral nerves had produced complete sympathetic paralysis. Lack of sweating of the anesthetized skin was noted, but recent investigations have shown that sweating may be markedly decreased without interfering with other functions of the sympathetic nerves (4). The authors point out that the circulation in the forearm is considerably increased immediately after sympathetic ganglionectomy, and they are unable to account for the difference between the effect of blocking a mixed nerve to a part of the limb and the effect when the sympathetic nerves supplying almost the whole limb are blocked.

The fact that heating the body produces a greater blood flow in the normal extremity than in the extremity which has been sympathectomized for some time cannot be used as evidence for the existence of vasodilator nerves (1). It has been repeatedly shown that there is an increase in tone in vessels deprived of their sympathetic nerve supply. If the comparisons between the blood flow in the normal and in the sympathectomized extremities are made after several days, the compensatory changes in the sympathectomized part make interpretation of the results difficult. The point at issue is whether, immediately after sympathetic section, the blood flow in the normal extremity can be increased by reflex stimulation to a level above that in the sympathectomized extremity.

It is possible to study the problem of whether vasodilator fibers are present in the sympathetic nerves supplying the extremities by determining the blood flow in the upper extremity before and after novocainization of the sympathetic ganglia supplying the part. The novocain blocks both vasoconstrictor and vasodilator stimuli. If vasodilatation is a passive process resulting from inhibition of reflex vasoconstriction, then blocking all vasoconstrictor impulses will cause as great a degree of vasodilatation as can be produced through reflex response to heating the body. On the other hand, if the sympathetic nerves carry both vasoconstrictor and vasodilator fibers, paralysis of both of these will produce some increase in blood flow because of removal of the vasoconstrictor impulses, but it will not produce as great an increase in blood flow as will reflex vasodilatation from heating the body, because the vasodilator impulses will also be blocked.

\section{METHOD}

These experiments were carried out on a normal, paid volunteer. The blood flow in the hand and forearm was measured by plethysmographic methods $(5,6)$. When the blood flow in the forearm was determined, the circulation to the hand was occluded by a tourniquet, distal to the forearm plethysmograph $(7,8)$.

The subject sat upright in a chair with the arms resting on a table in front of him. The parts to be studied were placed in the plethysmograph and surrounded by water of the desired temperature for at least $\mathbf{3 0}$ minutes before the experiment was started. Control flows were taken.

The sympathetic ganglia supplying the right upper extremity were then paralyzed by the paravertebral injection of novocain. The spinous processes of the 7th cervical and upper 5 dorsal vertebrae were marked with a skin pencil and scratches were made $4 \mathrm{~cm}$. lateral to each spinous process. The skin over the region was then disinfected, and wheals were raised by injecting 1 per cent procain hydrochloride into the skin surrounding each scratch. A 3 inch, No. 22 gauge needle was inserted into the wheal opposite the 3rd spinous process, and advanced perpendicular to the skin, toward the lower border of the rib, until it impinged in the general region of the tubercle. After contacting the rib, the needle was withdrawn slightly, a 2 cc. syringe full of 1 per cent procain was attached, and the needle was advanced slowly in a transverse plane at an angle of about 30 degrees to the sagittal plane of the body. Procain was infiltrated along the inferior margin of the costovertebral joint, the neck, and the head of the rib, so that there was no lasting 
TABLE I

Summary of the experimental data on the hand

\begin{tabular}{|c|c|c|c|c|c|}
\hline & \multicolumn{2}{|c|}{$\begin{array}{c}\text { Temperature of water in } \\
\text { plethysmograph }\end{array}$} & \multicolumn{2}{|c|}{$\begin{array}{l}\text { Blood flow in cc. per minute } \\
\text { per } 100 \text { cc. of tissue }\end{array}$} & \multirow{2}{*}{ Remarks } \\
\hline & Right & Left & Right & Left & \\
\hline Resting $\ldots \ldots \ldots \ldots \ldots \ldots \ldots \ldots$ & $30^{\circ} \mathrm{C}$. & $30^{\circ} \mathrm{C}$. & 1 & 1 & $\begin{array}{l}\text { Room temperature: } 21^{\circ} \mathrm{C} \text {. } \\
\text { Body exposed. }\end{array}$ \\
\hline $\begin{array}{l}\text { Reflex vasodilatation induced by im- } \\
\text { mersing legs in hot water at } 43^{\circ} \mathrm{C} .\end{array}$ & $30^{\circ} \mathrm{C}$ & $30^{\circ} \mathrm{C}$. & 8 & 11 & $\begin{array}{l}\text { The subject is warm all } \\
\text { over and has begun to } \\
\text { sweat. Vasodilatation is } \\
\text { not complete. }\end{array}$ \\
\hline $\begin{array}{l}\text { After right paravertebral block. } \\
\text { Heating of legs continued . . . . . . }\end{array}$ & $31^{\circ} \mathrm{C}$. & $31^{\circ} \mathrm{C}$. & 32 & $0-?$ & $\begin{array}{l}\text { On the left, the vasocon- } \\
\text { strictor effect of pain has } \\
\text { overcome the vasodilator } \\
\text { effect of heating the body. } \\
\text { There is no vasoconstric- } \\
\text { tor effect on the right be- } \\
\text { cause of the paraverte- } \\
\text { bral block. }\end{array}$ \\
\hline block. Heating of legs continued .. & $31^{\circ} \mathrm{C}$. & $31^{\circ} \mathrm{C}$ & 13 & 13 & $\begin{array}{l}\text { Blood flow in both hands } \\
\text { gradually rising as heat- } \\
\text { ing of the body continues. }\end{array}$ \\
\hline $\begin{array}{l}\text { Temperature of water surrounding } \\
\text { right hand raised to } 43^{\circ} \mathrm{C} \text {. Heat- } \\
\text { ing of legs continued.......... }\end{array}$ & $43^{\circ} \mathrm{C}$ & $31^{\circ} \mathrm{C}$. & 34 & 19 & $\begin{array}{l}\text { Full vasodilatation in the } \\
\text { right hand from a combi- } \\
\text { nation of local heat and } \\
\text { heating the body did not } \\
\text { produce a significantly } \\
\text { greater blood flow than } \\
\text { was produced by block of } \\
\text { the sympathetic ganglia. }\end{array}$ \\
\hline
\end{tabular}

discomfort. The needle was inserted until it struck the body of the vertebra. In each instance, the patient described paresthesias along the intercostal nerve as the needle was advanced the last 1 or $2 \mathrm{~cm}$.

The 4th and 5th intercostal spaces were needled in succession, and then the 2 nd and the 1st. Finally, a needle was inserted opposite the 7 th cervical spine in a direction parallel to the needle in the first space. Because of the position of the patient, the upper 3 needles had to be angulated downward slightly as they skirted the neck of the ribs. Ten cc. of alkaline procain (9) were injected slowly in each interspace. After sympathetic paralysis developed, as evidenced by vasodilatation and the development of Horner's syndrome on the injected side, the needles were removed.

Reflex vasodilatation was produced by immersing the legs in hot water $\left(43^{\circ} \mathrm{C}\right.$.). Heating the body does not produce maximal vasodilatation in the hand when the water in the plethysmograph is maintained at $30^{\circ} \mathrm{C}$. (8). Therefore, when the full degree of vasodilatation which could be induced by heat was desired, the part under observation was surrounded by hot water. When the water was in contact with the skin, as in the hand plethysmograph, the temperature was kept at $43^{\circ} \mathrm{C}$. When the water was separated from the skin by a thin rubber membrane, as in the forearm plethysmograph, the temperature was maintained at $46^{\circ} \mathrm{C}$.

\section{RESULTS}

Blood flow in the hands. The data from this experiment are summarized in Table I. In this paper, the blood flow is recorded as cc. of blood flow per minute per $100 \mathrm{cc}$. of tissue enclosed within the plethysmograph. With the temperature of the water in the plethysmographs at $30^{\circ}$ and the arms, chest, and lower extremities exposed, the blood flow in each hand was $1 \mathrm{cc}$. per minute per $100 \mathrm{cc}$. of tissue (Figure 1-A). Room temperature was $21^{\circ} \mathrm{C}$. The lower extremities below the knees were then immersed in water at $43^{\circ} \mathrm{C}$. Body heating by this means was continued throughout the entire experiment. Partial reflex vasodilatation occurred and the blood flow in the hands increased, rising to a level of $8 \mathrm{cc}$. in the right, and $11 \mathrm{cc}$. in the left (Figure 1-B). At this time, normal vasomotor activity, which is dependent on the integrity of the sympathetic nerves, was demonstrable in both hands (Figure 2-A). The sympathetic ganglia supplying the right upper extremity were then paralyzed by right paraverte- 

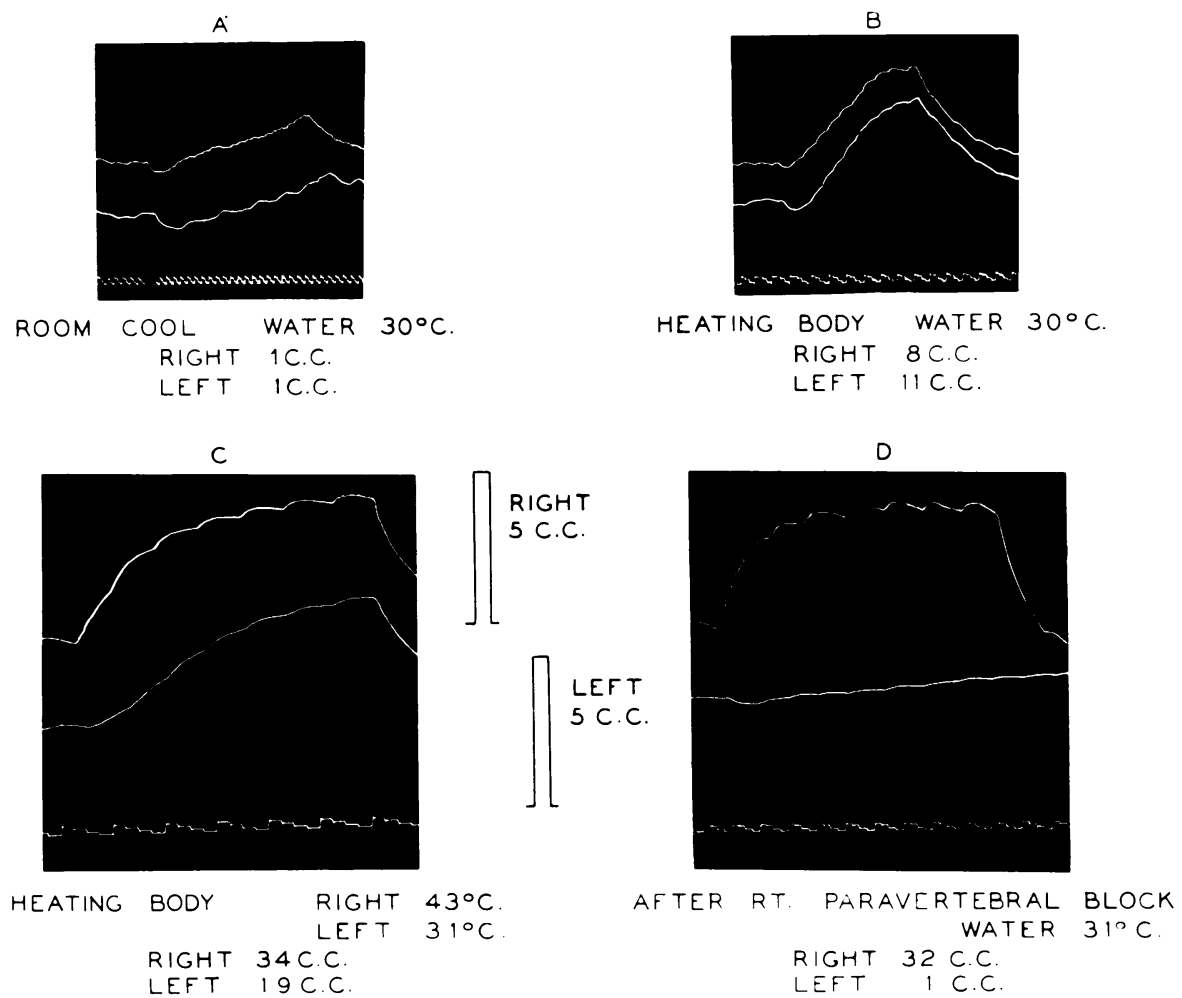

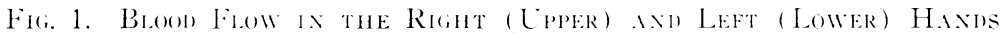

Recorded in cc. of blood per minute per $100 \mathrm{cc}$ of hand. A. Control. Body exposed. room temperature $21^{\circ} \mathrm{C}$., water in plethysmograph at temperature of $30^{\circ} \mathrm{C}$. B. After immersing lower legs in water at a temperature of $+3^{\circ} \mathrm{C}$. The blood flow has increased in both hands. C. Legs still in water at $43^{\circ} \mathrm{C}$. Water about right hand at temperature of $+3^{\circ} \mathrm{C}$. Blood flow increased in both hands but greater in the one surrounded by the hot water. D. After right paravertebral block. Water about both hands at temperature of $31^{\circ} \mathrm{C}$. Note that blocking the sympathetic nerves produces as great an increase in blood flow as the combination of local heat and heating the body (Figure 1-C). The pain produced by inserting the needles for the paravertebral block has caused marked vasoconstriction in the leit hand.

bral injection of novocain. The pulse waves in the right hand showed a marked increase in size. and the vasomotor activity which was present before the block disappeared completely (Figure 2-B). A (leep breath, or pinching the skin, no longer produced rasoconstriction in the right hand. There was a marked Horner's syndrome on the right. The skin of the right face and arm was warm and flushed. and the veins, full. There was no sweating. Note that the left hand now showed no spontaneons variations in volume. but for a different reason. The pain caused by putting the needles in place for the paravertebral block had produced generalized vasoconstriction in all parts of the skin except where the sympathetic nerves had been paralyzed. The skin of the left arm was cold and clammy. The ressels of the left hand were fully constricted, and the blood flow, very slow. The vasoconstrictor effect of pain had completely overcome the vasodilator effect of heating the body. The blood flow in the right hand was now $32 \mathrm{cc}$. (Figure 1-D)) ; that in the left hand was too low to be measured for some minutes, but it gradually increased as the effects of the pain decreased. As the effect of the novocain wore off. the blood flow in the right hand gradually decreased. Because of the continued body heating. the blood flow in both hands remained somewhat 
A

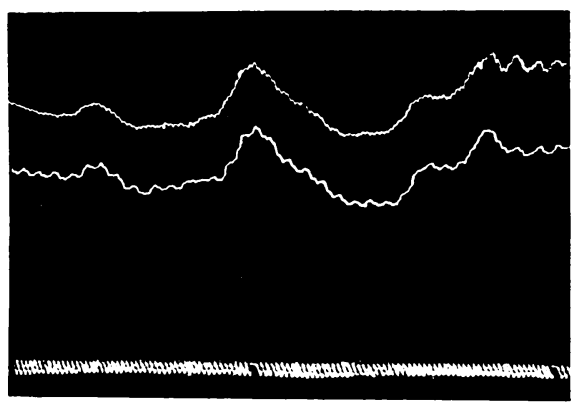

CONTROL

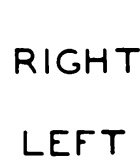

AFTER NOVOCAIN - BLOCK OF RIGHT SYMPATHETIC GANGLIA

Fig. 2. Vasonotor Respoxses in the Right (Lpper) axd Lefat (Lower) Haxils

A. Control. Normal vasomotor activity in both hands. B. After right paravertebral block. The arterial pulsations are very marked in the right hand. and there is no evidence of racomotor activity. There is marked vasoconstriction in the left hand because of the pain caused by inserting the needles for the block.

above the level present before the block. Spontaneous vasomotor activity was now present in both hands.

This portion of the experiment clemomstrated that the blood flow in the right hand, already increased by reflex vasodilatation from heating the body. was further increased by blocking all the sympathetic nerves to the part. It was obvious. however. that complete vasodilatation was not present in the hand before the paravertebral block. It has been demonstrated that, in the hand. complete vasodilatation is not produced by heating the body if the temperature of the water surrounding the hand is maintained at $30^{\circ} \mathrm{C}$. (8). The maximal rasodilatation that can be induced by heat will occur if the water is maintained at a temperature of $43^{\circ} \mathrm{C}$. Therefore, in orcler to compare the effect of paravertebral block with the full vasodilator effect of heat, it was necessary to raise the temperature of the water surrounding the right hand.

The water about the right hand was heated to $43^{\circ} \mathrm{C}$.. that about the left hand remained at $31^{\circ}$ C. Twenty minutes later blood flows were recorded in both hands; that in the right was $34 \mathrm{cc}$ : that in the left. $19 \mathrm{cc}$. The blood flow in the left hand had risen because of the continued body heating produced by having 3 extremities immersed in water at $43^{\circ} \mathrm{C}$. The flow in the right hand had increased above that in the left hand because of the combined effect of local heat and body heating. It is significant that this combination

TABLE II

Summary of experimental obseriations on right forearm

\begin{tabular}{|c|c|c|c|}
\hline & $\begin{array}{l}\text { Temperature of water } \\
\text { in plethysmograph }\end{array}$ & $\begin{array}{c}\text { Blood flow in cc. per } \\
\text { minute per } 100 \mathrm{cc} \\
\text { of tissue }\end{array}$ & Remark: \\
\hline Resting . . . . . . . . . . & $31^{\circ} \mathrm{C}$. & 2 & Room temperature: $22^{\circ} \mathrm{C}$ \\
\hline After right paravertehral block.... & $31^{\circ} \mathrm{C}$. & $1 \overrightarrow{2}$ & $\begin{array}{l}\text { Block satisfactory as shown by hot } \\
\text { dry right hand with rapid bloos } \\
\text { flow. The left hand was moist } \\
\text { and cold. }\end{array}$ \\
\hline Recovery stage $\ldots \ldots \ldots \ldots \ldots \ldots$ & $31^{\circ} \mathrm{C}$. & 2 & \\
\hline $\begin{array}{l}\text { Temperature of water surrounding } \\
\text { right forearm raised to } 46^{\circ} \mathrm{C} \ldots \ldots\end{array}$ & $46^{\circ} \mathrm{C}$. & 12 & $\begin{array}{l}\text { The temperature was raised to } 46^{\circ} \mathrm{C} \\
\text { rather than } 43^{\circ} \mathrm{C} \text {. because in the } \\
\text { forearm plethysmograph the water } \\
\text { is separated from the skin by a thin } \\
\text { rubber membrane. }\end{array}$ \\
\hline
\end{tabular}




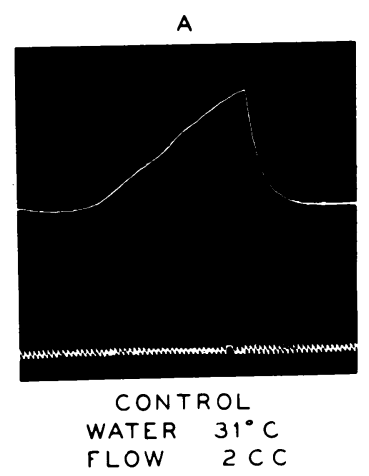

B

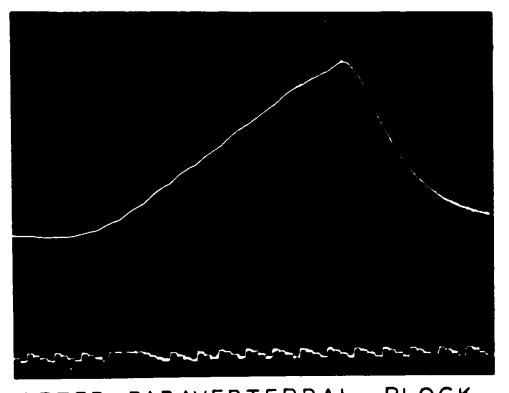

AFTER PARAVERTEBRAL BLOCK

WATER $31^{\circ} \mathrm{C}$.

FLOW 12 C.C.

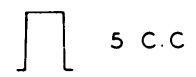

C

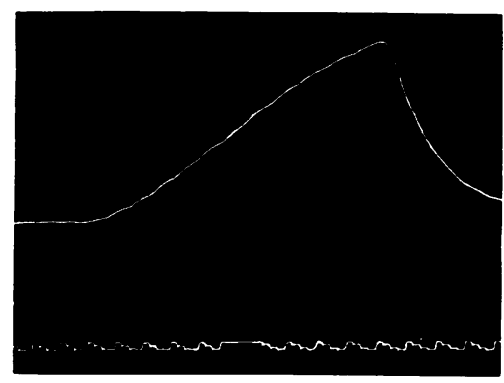

WATER $46^{\circ} \mathrm{C}$

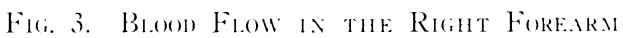

Recorded as cc. per minute per $100 \mathrm{cc}$. of forearm. Circulation to the hand occluded. A. Control. Water in plethysmograph at $31^{\circ}$ (. B. After paravertebral block. Water in plethysmograph at $31^{\circ} \mathrm{C}$. Note marked increase in blood flow. C. After water in the plethysmograph had been at temperature of $46^{\circ}$ C. for iorty minutes.

of local and body heating caused no greater vasodilatation in the right hand than did block of the sympathetic nerve supply. It was, therefore. concluded that there were no vasodilator filsers in the sympathetic nerves supplying the hand. because removal of all sympathetic impulses produced complete vasodilatation.

Blood flow in the forcarm. Because the rascular reactions of the forearm differ somewhat from those of the hand $(7,8,10)$, it was still possible that the sympathetic fibers supplying the forearm might contain vasodilator fibers. Therefore, at another time, the response of the ressels of the forearm after blocking of the sympathetic nerve supply was studied (Table II).

The sulbject sat upright in a chair, with the right forearm in a plethysmograph. The water in the plethysmograph was maintained at a temperature of $31^{\circ}$ ( . The resting blood flow was 2 cc. per minute per 100 ce. of forearm. The sympathetic nerves to the right upper extrenity were then blocked by the paravertebral in jection of novocain. This produced a marked Horner's syndrome on the right. The skin of the right face and right arm became warm. flushed, and dry. The veins were full. The skin of the remainder of the borly was pale. cold, and covered with perspiration from the pain which was produced by putting the needles in place for the injection. The blood flow in the right forearm was $12 \mathrm{cc}$. after the block. As the effect of the norocain wore off the blood flow returned to the control level. The temperature of the water in the plethysmograph was then raised to $46^{\circ} \mathrm{C}$. Forty minutes later the blool flow in the forearm was $12 \mathrm{cc}$. As in the hand. paralysis of the sympathetic nerves had produced as great rasodilatation as did the application of local heat. It was not considered necessary to 
determine the blood flow after body heating because it has been shown that the application of local heat to the forearm produces more complete vasodilatation than is obtained from heating the body (8).

\section{COMMENT}

This investigation was carried out on only one subject. In each set of experiments, data were collected before, during, and after the paravertebral block. Because of the nature of the investigation, it was possible to make repeated observations during each phase of the experiment. It is felt that this type of carefully planned experiment, in which the subject serves as his own control, is more valuable than less complete observations on several subjects.

Other investigators have not produced as great a degree of vasodilatation from paravertebral block as they have from heating the body $(6,11)$. They made no attempt, however, to determine whether the injection of novocain had completely destroyed all evidences of sympathetic activity. Their results are comparable to those obtained by us while the effect of the novocain was wearing off. Partial block produces some increase in blood flow, but not as much as is caused by body heating. It has been previously shown that the majority of the vessels in the hand are fully dilated by local heat (8). The fact that blocking sympathetic impulses to the hand produces as complete vasodilatation as does heating the part indicates that most of the vessels in the hand are under the influence of the sympathetic nervous system. As will be pointed out below, the forearm differs from the hand in this respect.

In the forearm, blocking of the sympathetic ganglia caused an increase in blood flow to the same level as that produced by local heat. It is known that in the forearm, local heat produces as great, or greater, vasodilatation as that produced by heating the body (8). Neither local heat, nor a combination of local heat and body heating, produces maximal vasodilatation in the forearm (8). Exercise causes much greater vasodilatation than occurs as a reflex response to heating the body, or than was produced in this subject by block of the sympathetic nerves. This indicates either that, in contrast to the hand, many of the vessels of the forearm are not under the control of the sympa- thetic nervous system, or that heat is not an adequate stimulus for producing reflex vasodilatation in the forearm. Experimental observations have shown that heating the body is the strongest known stimulus for reflex vasodilatation of the vessels of the forearm. The vasodilatation induced by arterial occlusion, exercise, and epinephrine is not reflex in origin. As the vessels of the skin of the hand have been shown to be under sympathetic control, it is logical to assume that the vessels of the skin of the forearm are also under sympathetic control, and that the difference in the reaction of the vessels of the hand and of the forearm to heat and sympathetic block is explained by the greater mass of muscle in the forearm. These observations suggest that the sympathetic nervous system plays little part in regulating the blood supply to the muscles.

Grant (12) has demonstrated that the local vascular effects of exercise are independent of the sympathetic nerves. Kunkel, Stead, and Weiss (8) concluded that local heat to the forearm caused much greater dilatation in the vessels of the skin than in the vessels of the muscles. They noted that though the resting blood flow could be greatly varied by raising or lowering the temperature of the water surrounding the forearm, vigorous exercise of the forearm produced approximately the same increase in blood flow above the resting level. It has also been shown that arterial occlusion produces a much greater blood flow in the forearm than occurs after reflex dilatation from heating the body, or from a combination of body heating and local heat to the forearm $(8,10)$. This again is in sharp contrast to the findings in the hand and foot, where local heat produces more nearly maximal vasodilatation. The reactive hyperemia in the forearm produced by the release of arterial occlusion is not altered by sympathectomy (10).

Patients with destruction of a lateral portion of the medulla oblongata, from thrombosis of the posterior inferior cerebellar artery, frequently show partial sympathetic paralysis. In certain of these patients, the vessels of the extremities on the side of the lesion are not able to constrict fully when the body is cooled, but they dilate normally when the body is heated (4). They resemble cases of unilateral peripheral sympathectomy in 
that the involved hand is the warmer one when the body is exposed in a cool room, but they differ from the unilateral sympathectomy in that warming the body produces as great an increase in blood flow in the involved hand as it does in the normal hand. The induction of this type of paralysis of vasoconstriction without disturbance of vasodilatation would be ideal in the treatment of Raynaud's disease. Heretofore, there have seemed to be two equally plausible explanations for this dissociation between vasoconstriction and vasodilatation: ( $a$ ) that the sympathetic nerves to the extremities contain both vasoconstrictor and vasodilator fibers and that the medullary lesion destroyed the central connections of the vasoconstrictor fibers without injuring the tracts concerned with vasodilatation; (b) that the sympathetic nerves contain only vasoconstrictor fibers, vasodilatation being simply inhibition of vasoconstriction, so that partial destruction of the central connections of the vasoconstrictor fibers interfered with the active process of vasoconstriction without disturbing the passive vasodilatation resulting from inhibition of vasoconstriction. The experimental data reported here indicate that the latter is the correct explanation. It is of interest that with the medullary lesion the remaining connections of the vasoconstrictor nerves are sufficient to prevent the vessels of the extremities from exhibiting the increase in tone which follows either pre- or postganglionic sympathectomy, though they are not capable of producing normal vasoconstriction on cooling the body. Therefore, inhibition of vasoconstriction still allows full normal vasodilatation to occur.

\section{SUMMARY AND CONCLUSIONS}

(1) On two occasions, the sympathetic ganglia supplying the right upper extremity of a normal subject were injected with novocain by the paravertebral route. The blood flow in the hand and forearm was measured before, during, and after the anesthetization.

(2) Complete absence of any vasomotor activity in response to sensory stimuli or deep inspiration indicated complete paralysis of the sympathetic ganglia supplying the right hand. The sympathetic paralysis produced a striking increase in blood flow. After the effect of the novocain had passed away, the right hand was immersed in water at a temperature of $43^{\circ} \mathrm{C}$. Local heat produced the same increase in blood flow in the right hand as had sympathetic paralysis.

(3) The fact that acute sympathetic paralysis produces nearly maximal dilatation in the hand indicates that most of the vessels supplying the hand are under control of the sympathetic nervous system.

(4) The fact that complete blocking of sympathetic ganglia produces full vasodilatation in the hand demonstrates that inhibition of sympathetic activity is sufficient to explain the vasodilatation which occurs in the hand when the body is heated. There is no necessity for postulating that the sympathetic nerves to the hand contain vasodilator fibers.

(5) In the forearm, paravertebral novocainization of the sympathetic ganglia caused a six-fold increase in blood flow. A similar increase in blood flow was produced by immersing the forearm in hot water $\left(46^{\circ} \mathrm{C}\right.$.). This indicates that removal of all sympathetic impulses to the vessels of the forearm produces as great a rise in blood flow as does heating the part. Inhibition of vasoconstriction adequately explains the increase in blood flow which occurs when the body is heated, and there is no need to assume that the sympathetic nerves to the forearm contain vasodilator fibers.

(6) The fact that neither heating the forearm nor injection of the sympathetic ganglia with novocain produces maximal dilatation in the forearm indicates that many of the vessels of the forearm are not under control of the sympathetic nervous system. It is suggested that the vessels of the skin of the forearm are under the control of the sympathetic nervous system, and that those of the muscle are not.

This investigation was carried out with the technical assistance of Miss Rosamond Piotti, S.B.

\section{BIBLIOGRAPHY}

1. Lewis, T., and Pickering, G. W., Vasodilatation in the limbs in response to warming the body; with evidence for sympathetic vasodilator nerves in man. Heart, 1931, 16, 33.

2. Bolton, B., Carmichael, E. A., and Stürup, G., Vasoconstriction following deep inspiration. J. Physiol., 1936, 86, 83. 
3. Grant, R. T., and Holling, H. E., Further observations on the vascular responses of the human limb to body warming; evidence for sympathetic vasodilator nerves in the normal subject. Clin. Sc., 1938, 3, 273.

4. Stead, E. A., Jr., Ebert, R. V., Romano, J., and Warren, J. V., Central autonomic paralysis. Arch. Neurol. and Psychiat., 1942, 48, 92.

5. Lewis, T., and Grant, R. T., Observations upon reactive hyperemia in man. Heart, 1925, 12, 73.

6. Freeman, N. E., The effect of temperature on the rate of blood flow in the normal and in the sympathectomized hand. Am. J. Physiol., 1935, 113, 384.

7. Grant, R. T., and Pearson, R. S. B., The blood circulation in the human limb; observations on the differences between the proximal and distal parts and remarks on the regulation of body temperature. Clin. Sc., 1938, 3, 119.
8. Kunkel, P., Stead, E. A., Jr., and Weiss, S., Blood flow and vasomotor reactions in the hand, forearm, foot, and calf in response to physical and chemical stimuli. J. Clin. Invest., 1939, 18, 225.

9. Walter, C. W., The basis of successful parenteral therapy. U. S. Nav. M. Bull., 1941, 39, 249.

10. Wilkins, R. W., and Eichna, L. W., Blood flow to the forearm and calf. 1. Vasomotor reactions: role of the sympathetic nervous system. Bull. Johns Hopkins Hosp., 1941, 68, 425.

11. Prinzmetal, M., and Wilson, C., Nature of peripheral resistance in arterial hypertension with special reference to vasomotor system. J. Clin. Invest., 1936, 15, 63.

12. Grant, R. T., Observations on the blood circulation in voluntary muscle in man. Clin. Sc., 1938, 3, 157. 